\title{
AMERICAN RHEUMATISM ASSOCIATION
}

\section{PROCEEDINGS OF THE SECOND INTERIM SCIENTIFIC SESSION}

\author{
December, 1955
}

Dr. Charles L. Short, President of the American Rheumatism Association, took the chair at the opening meeting of the second interim scientific session held on December 9, 1955, at the Clinical Center, National Institutes of Health, Bethesda, Maryland. He thanked those who had arranged the scientific programme and social events, and Dr. J. A. Shannon, Director of the National Institutes of Health, welcomed the members of the American Rheumatism Association and their guests.

Abstracts of eighteen papers and the discussions thereon are printed below, together with the titles of 23 papers presented tut not read.

Uric Acid Formation in Patients with Gout. The Incorporation of 4-Amino-5-Imidazolecarboxamide- $\mathrm{C}^{13}$ into Uric Acid. By J. E. Seegmiller, Leonard Laster, and DeWitt Stetren, JR., Bethesda, $M d$.

By studying the incorporation of glycine- $\mathrm{N}^{15}$ into uric acid, Benedict and others $(1952,1953)$ have shown that some gouty patients appear to possess a "shunt mechanism" for urate biosynthesis. Because animal and bacterial systems incorporate 4-amino-5-imidazolecarboxamide, "AIC", into purines at a stage of the biosynthetic chain between glycine and uric acid, AIC was synthesized with $\mathrm{C}^{13}$ in the four position and was fed to human subjects in order to learn more about the chemical reactions involved in the proposed "shunt mechanism".

When $14 \mathrm{mg}$. per kilo AIC-C ${ }^{13}$ was fed to two normal males, 23 per cent. was incorporated into urinary uric acid and 20 per cent. was recovered unchanged in the urine without significant isotope dilution (Seegmiller and others, 1955). From the results it was concluded that AIC is incorporated into uric acid promptly, but there is an additional contribution of isotope to uric acid from a body pool with a slow turnover rate, presumed to arise largely from tissue purines. A pool of free AIC in the body was not detected. Glycine- $\mathrm{N}^{15}$ was fed with the AIC and, in the dosage level used, AIC appeared capable of inhibiting the de novo synthesis of uric acid from glycine.

Similar studies have been performed on patients with gout who belong to the class showing normal incorporation of $\mathrm{N}^{15}$ into uric acid. Although there is some suggestion of an increased total incorporation of AIC into uric acid in these patients, our data also shows many points of similarity to the pattern of incorporation seen in the normal. AIC exerts a depressant effect on the de novo synthesis of uric acid from glycine in gouty patients so far studied, as well as in normal subjects.

Discussion.-DR. Edward F. Rosenberg (Chicago, Ill.): I wonder if this discovery that uric acid formation is decreased may have a clinical application? Shall we be able to use this material in the treatment of gouty patients who may be forming uric acid excessively?

Dr. Seegmiller: It is very unlikely that it would have a use in treatment. We found in the 2 days following the administration of this dose of AIC that $200 \mathrm{~g}$. extra uric acid was excreted in the urine, which resulted, presumably, from this very direct and rapid conversion of AIC to uric acid.

The possibility of alleviating an acute attack of gout by suppressing uric acid precursors has, of course, occurred to us, and we have tried it in a few cases, but without any real definitive results.

Dr. L. Maxwell Lockie (Buffalo, N.Y.): Has Dr. Seegmiller performed any determinations on these possible precuisors in which some of the AIC may be present? This would be of great interest to those of us who are concerned with fundamental studies of uric acid metabolism. This presentation of factual evidence represents a tremendous amount of time and effort, and it is nice to have more body pool determinations reported.

Dr. Seegmiller: No, we have not attempted yet to isolate and characterize any metabolic products of AIC other than the uric acid.

\section{REFERENCES}

Benedict, J. D., Roche, M., Yü, T. F., Bien, E. J., Gutman, A. B. and Stetten, D., Jr. (1952). Metabolism, 1, 3.

Yü, T. F., Bien, E. J., Gutman, A. B., and Stetten, D., Jr. (1953). J. clin. Invest., 32, 775

Seegmiller, J. E., Laster, L., Stetten, D., Jr. (1955). J. biol. Chem., 216, 653 .

Pathological Study of the Renal Lesions found in $\mathbf{2 7}$ Patients with Gout. By JoHn G. MAYNe, Rochester, Minn.

Inasmuch as urate diuresis is a basis of the modern therapy of gout, renal disease in patients with gout is of serious import. The kidneys of 27 patients with gout were studied at necropsy to determine the frequency and type of renal lesions present.

Fourteen patients had had symptoms or signs of gout for less than 10 years; thirteen patients had had such evidence for 11 or more years. 
In these 27 patients, renal disease was the major cause of death before the age of 40 . Six patients died in uraemia of renal disease, eight died of various types of heart disease, five of neoplasms, and eight of other causes.

The kidneys of eight patients were essentially normal and contained no urate deposits by gross or microscopic observation. Eight patients had small kidneys, and eight had atrophic kidneys. In three cases pathological details were incomplete. Urate deposits were found in seventeen of these nineteen cases $(63$ per cent. of the total).

Urate deposits and those tissue alterations produced by them were the only lesions pathognomonic of gout. The intra- or extra-tubular location of the urate deposits could not be satisfactorily determined by histological study alone. Vascular lesions other than those found in five cases of glomerulonephritis, one of chronic pyelonephritis, and three of essential hypertension were compatible with the age group comprising the series.

The relative frequency of the lesions of glomerulonephritis was not explained.

Discussion.-Dr. Leonard LASTER (Bethesda, Md): Were any of these patients receiving Benemid for long periods of time? If so, did the ones who received Benemid show fewer deposits of urate in their kidneys?

Dr. MAYNE: None of the patients in this study had had Benemid.

Dr. John N. Swanson (Toronto, Ont., Canada): I have been studying 176 patients with gout, of whom 38 had clinical or laboratory evidence of kidney function impairment. Eight of these came to autopsy, and four had urate deposits, similar to those you have mentioned, while three apparently had chronic glomerulonephritis.

One, however, had congenital hypoplasia of the left kidney and was particularly interesting as this may be of aetiological significance. The patient concerned had been a French-Canadian, and I do not believe gout is a very common disease in his race. He was one of fifteen children, and there was no family history of gout amongst them, or any other relatives as far as was known. During the recent war he was wounded in the abdomen, and in the subsequent hospitalization it was noticed that his left kidney was not functioning. It was thought at first that the bullet had severed his left ureter. He subsequently developed pyelonephritis in the remaining kidney and, during the last 3 or 4 years of his life, had frequent attacks of gouty arthritis. At autopsy it was discovered that the left kidney was hypoplastic, and only a few mesonephrons were seen microscopically. It is surely more than just coincidence that gout developed in this man who had one kidney absent, and the other diseased, when his race has gout but infrequently, and the rest of his family was free from gout.

Dr. MAYNe: I think that is a most interesting study. The one case of chronic pyelonephritis which I mentioned had occurred in a man who had a single kidney, congenitally. He had been troubled with recurring attacks of ureteral obstruction from the age of 15 or 18 . He had been repeatedly cystoscoped during his lifetime. This I think is an interesting comparison with your French-Canadian patient.

Dr. Joseph J. Bunim (Bethesda, Md): I wonder if, in retrospect, Dr. Mayne could distinguish by clinical and laboratory evidence the tubular lesions from the kidneys in gouty patients which show vascular or glomerular lesions.

I think about 3 years ago Dr. Modern and his associates of California reported that they could segregate the lesions which were isolated or confined to tubular changes and were not associated with glomerular or vascular changes. They believed that these might be recognized clinically by a dissociation of certain laboratory and clinical features. For example, such patients had impairment of renal function, low excretion of dye, hyposthenuria, and low clearance, but hypertension, albuminuria, and a significant amount of cylindruria were absent. Such patients, they felt, had a much better prognosis than gouty patients with non-specific glomerular or vascular lesions.

DR. MAYNE: That is most interesting. In my series renal function studies using a dye retention (i.e. PSP, and so forth) were not reported, so I cannot answer that part of the question.

The tubular lesions did seem to be associated primarily with patients who had other forms of renal disease. Thus, in the five cases of glomerulonephritis, all but one patient showed evidences of tubular lesions with urate deposits; in the three cases of nephrosclerosis, all had tubular lesions with urate deposits.

There were a number of other patients who had urate deposits in the tubules. These had no sign of other than a minimal arterio- or arteriolo-sclerosis which usually seemed compatible with their ages which were all in the 60 s and 70 s, except one man who was 90.

Rheumatoid Disease in Swine. By G. M. Neher, L. P. Doyle, C. B. Swenson, and Dennis SiKes, Lafayette, Ind., and Athens, Ga.

Since rheumatoid disease was the primary cause for the condemnation of swine carcasses in 1954, it is one of the major problems in animal health to-day. The disease in swine shows many similarities to rheumatoid arthritis in the human being, and it is conceivable that experimentation with swine may facilitate a better understanding of the corresponding disease in man.

The symptoms of arthritis in swine are swollen painful joints accompanied by severe lameness with apparent muscular soreness. The pathological changes in the joints are essentially proliferative and non-suppurative with numerous foci of lymphocytes. Granulomatous proliferations of the synovial capsule and villi occur with pannus formation, destruction of the articulating cartilage and subchondral cellular reactions. Intra-

articular fibrous adhesions are a common feature.
Radiographically, a narrowing of the joint spaces and $N$
$N$ osteophyte formations can be observed from the third $\mathrm{W}$ to fourth month. This is followed by some rarefaction of adjacent bone and massive exostoses which may result 0 in ankylosis of the joints. The authors frequently failed $\frac{D}{\Phi}$ to isolate organisms from the affected joints 6 months $\stackrel{?}{?}$ after exposure even though the arthritic process continued unabated.

Arthritis occurs naturally on farms as a chronic manifestation of swine erysipelas which is an acute and $\cong$ infectious disease caused by the bacterium Erysipelothrix $\stackrel{D}{\circ}$ 
rhusiopathiae. Using 191 swine, the authors were able to reproduce the disease with this organism by seven different exposure procedures. 35 per cent. of the animals died of the acute disease and 40 per cent. of the survivors developed chronic arthritis. When 95 animals were vaccinated and subsequently challenged, marked anaphylactic-type shock reactions were evident. The death rate due to the acute form of the disease was markedly reduced, but arthritis developed in between 90 and 100 per cent. of cases. These findings strongly suggest the possibility that sensitization is an important factor in the aetiology of the disease.

Swine with advanced rheumatoid disease respond very well to cortisone therapy; ACTH seems more beneficial in early cases.

Discussion.-DR. Morris SpIElberg (Brooklyn, N. Y.): Did any of these swine become pregnant and, if so, did it in any way change the progress of the type of response?

Dr. NeHER: We have made some attempts to breed from arthritic sows, but these attempts have failed. Females with advanced rheumatoid disease usually fail to exhibit any of the overt signs of oestrus and it is probable that they are not having regular ovarian cycles. None of the swine in the experiment reported here became pregnant.

Dr. RAlPH J. WeDGWOOd (Cleveland, Ohio): First, is there any hereditary nature to the disease; and, secondly, is there any record of age at onset, and does it bear any relationship to what we call puberty in man?

DR. NEHER: There seems to be no hereditary indication in this particular disease. To the casual observer there might seem to be, since droves of swine on different farms show marked variations in the degrees of immunity.

The bacterium Erysipelothrix rhusiopathiae is very widespread in nature, and the variations in the different families of swine quite possibly reflect only the difference in the amount of immunity acquired following clinical or subclinical experiences with the organism. We had considerable difficulty in locating a drove of swine in which the disease had not occurred since the herd was established 12 years previously, so it was difficult to obtain susceptible swine.

In answer to your second question, there does seem to be an age relationship. Ordinarily young animals up to 3 months of age do not develop this type of rheumatoid disease. I have seen it on occasion but it is extremely rare. In animals over 3 months of age the disease is much more prevalent, and in fact domesticated swine begin to reach puberty at about 3 months of age.

Dr. OSCAR SWINEFORD (Charlottesville, $\mathrm{Va}$ ): Did you attempt to desensitize these animals? Is this organism pathogenic in animals other than swine?

Dr. NeHER: We did not attempt to desensitize the animals other than by allowing them to go untreated for a period of time.

So far as the pathogenicity of E. rhusiopathiae to other animals is concerned, it is highly pathogenic in such laboratory animals as mice and pigeons, and these two species are used frequently in identifying the organism. Erysipelothrix rhusiopathiae has been isolated from arthritic lambs and calves, but the arthritis produced in these animals does not seem to progress to the true rheumatoid type.

The organism has also been isolated from goats, horses, chickens, turkeys, and man.
Dr. Morris A. Bowie (Bryn Mawr, Pa): I should like to congratulate Dr. Neher and colleagues for bringing into sharp focus this problem which has intrigued people working in the rheumatic field for a long time. A number of years ago when Dr. Rosenthal and I were trying to elucidate some of the factors involved in the degeneration of cartilage, it became apparent that the most marked changes seen in abattoir material were in joints of the fore extremity, regardless of the age of the animal from which the material was selected. We reasoned that the prominence of the degenerative changes in the forelimbs was due to the fact that cattle usually rise from the ground using their forelimbs. Did most of the material which you showed come from the forelimbs of hogs?

Also, what is the normal life span of the average pig? I was impressed by the high incidence of osteophyte formation within a short period in the spine and what seemed to be the apparent disappearance of the pannus after an appreciable period. Certainly this most interesting study deserves further investigation.

Dr. NeHER: In so far as the life span of a hog is concerned, here we have, as you can recognize, a rather curious situation. Ordinarily swine are sent to market at about 6 to 7 months of age, at which time they weigh between 200 and $240 \mathrm{lb}$., depending upon how good the farm management has been.

I think that swine about 6 to 7 years old would be considered to approach senility. Ordinarily, under farm conditions, the animals are not kept this long, and we very rarely if ever see swine of this age. Animals that are kept past the marketing age are used for breeding. After sows have farrowed four or five litters (two litters being born each year), in many instances they become careless mothers, develop lactation difficulties, or have litters of reduced size, and are subsequently sold for slaughter. Consequently at our veterinary department we very rarely see swine which are over 5 years of age.

Dr. Antoinette Popovici (Washington, D.C.): What is the sex ratio in rheumatic disorders in swine? Have you found any relationship between the incidence of this disease and obesity in swine or any correlation between the accumulation of adipose tissue and the degree of rheumatic involvement?

DR. NeHER: Through selective breeding for many years swine have been evolved which yield carcasses with a high fat content. The average back-fat thickness over the carcass of a butchered hog may well be in the neighbourhood of $1 \frac{1}{2}$ to 2 in., so that one might say that swine in general are quite obese animals.

Our experiments were not designed to study the relationship of obesity to the incidence of acute swine erysipelas or arthritis. The animals used were about the same size and age and carried roughly the same degree of what livestock people call conditioning or fat over the body. Consequently our experimental evidence will not afford a precise answer to your question, but it is generally believed that fat swine are more susceptible to acute swine erysipelas than leaner swine of the same age. The body temperature in this disease will frequently rise to 108 and even $109^{\circ} \mathrm{F}$., and since more obese animals have greater difficulty in dissipating body heat the course of the disease is usually more acute and the mortality higher. The normal temperature in a pig will vary quite markedly between 100.4 and $104^{\circ} \mathrm{F}$. One cannot say that the incidence of rheumatoid arthritis in swine is greater in obese animals, since a loss of body weight and general 
inanition occurs concomitantly with the progress of the disease.

There seems to be no sex difference in this disease. The 191 animals reported on to-day were roughly half females and half barrows. A barrow is a male which has been castrated prior to puberty; swine producers routinely follow this practice except when certain animals are saved for breeding purposes. We have examined a few boars with naturally occurring rheumatoid disease, but not enough to establish whether or not sex differences are present.

Dr. Morris Ziff (New York, N.Y.): Have you cultured the chronic tissue lesions for Erysipelothrix rhusiopathiae?

DR. NEHER: After we challenge these animals intravenously and they have the acute disease, we can isolate $E$. rhusiopathiae from all the parenchymatous tissues until after the fever subsides. Then we are able to isolate the organism quite routinely from the regional lymph nodes which drain the limbs where joint involvement has taken place, as well as from the affected joints.

However, isolation of the organism from the joints of chronic cases of over 6 months' duration is extremely difficult. We rarely isolate the organism after this time, although the proliferative changes in the joints may be by no means advanced at that time. Thus, it would seem that rheumatoid disease progresses unabated in the absence of the micro-organism.

DR. MORRIS ZIFF: Is chronic arthritis in association with $E$. rhusiopathiae infection ever seen in man? I know the acute disease will produce arthritis, but that is pyogenic. Do you know whether a chronic sterile polyarthritis is ever seen in man?

DR. NeHER: In man, E. rhusiopathiae causes a skin lesion called an erysipeloid. It is my impression that no experimental evidence is available which would incriminate this bacterium as an aetiological factor in arthritis in man.

DR. MORRIS ZIFF: Septic arthritis has been reported, but it is important to know whether any of the septic cases ever go on to chronic arthritis.

I asked Dr. Neher for samples of serum from infected swine and received from him eighteen sera which we tried to absorb to do the sheep agglutination test. There was a lot of heterophil antibody in the sera and we were able to absorb only nine sera successfully. We tested these nine, three of which were from controls and six from arthritic swine. The three controls gave completely negative results. Of the six from arthritic swine, four showed agglutination in a titre of 1 in 14. This is a borderline titre, but in human sera we should regard them as positive.

I do not know the significance of the sheep cell agglutination test in swine, or whether this observation is repeatable, and I do not know whether a raised heterophil antibody titre would invalidate the results, but the results are suggestive.

DR. NEHER: I am very pleased to hear these results, and I shall be happy to draw more blood samples and send them to Dr. Ziff for further experiments.

Dr. Charley J. Smyth (Denver, Colo.): Our veterinarian friends have again called our attention to a disease in swine which in some respects resembles rheumatoid arthritis in man. In Michigan in 1939 and 1940 we became interested in trying to find an experimental $\leftrightarrows$ animal that might be suitable to study as a counterpart to man, and we were fortunate in obtaining about $150 \mathrm{~s}$ ? hogs from one of the abattoirs in Detroit. We studied these sections microscopically and found changes that are not dissimilar to those that have been described to-day; $\vec{\sigma}$ but on reviewing them with the chief of our pathology department at that time, we were assured that this was primarily a suppurative disease and, with the knowledge $\frac{\omega}{\partial}$ that erysipelas is a common illness in swine, we felt $\mathbb{\mathscr { Q }}$ that the proliferative changes were probably an irritative phenomenon in a previously damaged joint, which was not comparable to the disease which we call rheumatoid $\overrightarrow{0}$ arthritis in man.

I think it would be interesting, in view of these recent $\overrightarrow{\vec{\omega}}$ studies, to study the carcases of these animals for vascular lesions, peripheral nerve lesions, subcutaneous nodules, and evidence of myocytic lesions which might support the idea that this disease is related to the human disease. $\vec{c}$

The term "rheumatoid" should not be used without $G$ great care in translating this data into human data.

Dr. Irvin Stein (Philadelphia, Pa): You obtained a high degree of arthritis on intra-articular injection. 음 Was that a local reaction or did the arthritis appear in other joints as well?

DR. NEHER: We did produce the disease in other joints, and the incidence of rheumatoid lesions in other $\bar{\rho}$ joints seemed to be as great as in the injected joints. In some cases the acute inflammation would subside in $\vec{c}$ the injected joints, and the disease would become or localized in other joints, indicating that we had set up a septicaemia in the animal by this particular route of exposure.

DR. Richard T. SMITH (Philadelphia, Pa): I have had $\bar{\partial}$ the opportunity of following this study for 3 or 4 years. Dr. Neher and his colleagues should be congratulated $\frac{\mathrm{O}}{\mathrm{D}}$ on their hard work. You cannot imagine what is required in order to develop chronic arthritis in pigs, $\overrightarrow{\vec{O}}$ since so many of them die simply because they will not 3 stand on their painful joints. These men were dedicated to their task to such an extent that every morning they went down to the pens, grasped the pigs by the ears and hauled them up on their front feet, and by the tail and hauled them up on their hind feet, so that they would eat. That is the way to prevent starvation and preserve the $\overline{0}$ life of the pig until the chronic changes have had time to 3 develop.

The acute changes which have been seen previously and were not considered to be too closely allied to rheumatoid arthritis present a different picture as time $ᄋ$ goes on. $X$ rays show evident calcification of the synovial membrane, which occurs rapidly in the pigs since $\frac{7}{O}$ they will not move a painful joint. This permits ankylosis to develop rapidly provided they live long $N$ enough.

A great deal more work was done than has actually $\mathrm{N}$ been reported, and there are other findings that are $\mathrm{N}$ comparable to and parallel with human rheumatoid $\omega$ arthritis. In the pig the Erysipelothrix disappears, the arthritis progresses, and the similarity to human arthritis becomes more marked.

DR. John H. VAughan (Richmond, $\mathrm{Va}$ ): Have you been $\stackrel{\mathscr{Q}}{?}$ able to induce this disease with dead organisms, both at the time of vaccination and in challenge?

DR. NeHER: We have experiments under way at $\mathbb{D}$ present in which 36 animals are involved, and we are attempting to produce rheumatoid disease in the absence 
of living organisms. All I can say at this time is that several necropsies have been performed and the results appear encouraging, but it will be another month or two before I can make a more definite statement than that. We may be on the right track in producing the condition in the absence of a living organism, but it also seems that we have to use at least the killed organism. There are certain antigenic properties in the organism itself whether living or dead, which seem to be necessary aetiological factors in the disease.

Dr. SAmuel Bachrach (Worcester, Mass.): Have you tried any other substances in an attempt to produce this disease in swine other than those you have mentioned?

DR. NeHER: We have not made any serious attempts to produce the disease with micro-organisms other than $E$. rhusiopathiae, chiefly because we had succeeded in producing a rheumatoid disease, resembling the naturally occurring disease in every respect, with this organism. We have examined the joints of several hundred field cases and, with very few exceptions, when the organism isolated from the joints was E. rhusiopathiae.

In cases of suppurative arthritis, which are quite rare in older swine, we have no difficulty in isolating pyogenic bacteria, usually streptococci and less frequently staphylococci. Although this type of arthritis is quite common in pigs several weeks old, it is probably not associated with the true rheumatoid disease of swine which usually occurs in animals over 3 months of age. When the rheumatoid changes are advanced we do not isolate organisms routinely.

Dr. Charles Ragan (New York, N.Y.): Dr. Stoerk at the Merck Institute has produced an arthritis in rats, with Freund's adjuvant and homologous lymphoid tissue, which has many similarities to that described by Dr. Neher in swine. There are, however, no remissions and no exacerbations after an initial period of 2 months. Is this also true in the swine arthritis? If so, I think it would fall into the same category as that described by Dr. Smyth: this is one insult which is not sustained over a period of years as is the case with rheumatoid arthritis.

Dr. NeHER: I am sorry that I failed to mention that in our swine remissions and exacerbations of the symptoms seem to be a very common feature until the disease has progressed for 2 to 3 months. After bony changes have begun to occur in the joints the disease usually progresses at a more uniform rate. However, remissions and exacerbations in the early stages of the disease are common features, as well as lameness which seems to have a tendency to shift to various joints. During the first 2 weeks the animals seem to be very lame in all leg joints. A week or two later one will observe that the lameness has shifted so that only one or two joints are involved. At this time, we begin to see marked swelling of the affected joints.

Dr. Robert Stecher (Cleveland, Ohio): Several years ago I visited the Equine Experimental Station in Newmarket, England, and they described an epidemic that they had had a year or so before in foals of acute arthritis which seemed similar to this, and I saw many preserved specimens. While I was there a new case was brought in and I saw the autopsy; the joints looked very much like the joints that you have shown here. They had been unsuccessful in isolating an organism in this disease.

I also saw dried specimens of the spines of horses that showed various signs of spondylitis and ankylosis and spur formation, and so forth, which looked very much like the specimen that you showed here. I have picked up specimens on the prairie in Wyoming, from horses that had been destroyed, that showed these lesions again. This seems to indicate that perhaps the infection is more important than we had heretofore thought.

DR. R. R. Williams (Bethesda, Md): We also had the opportunity of testing some of these sera from swine with rheumatoid disease, and our results were essentially the same as Dr. Ziff's. All our tests were negative, but I would suggest that possibly the sensitization of the sheep cells with swine antiserum to sheep cells might produce some agglutination. We know that bovine gamma-globulin is quite different in reactivity from the agglutinating material in human rheumatoid serum, and that there is little difference between human and rabbit gamma-globulin.

DR. NEHER: I should like to say a word in regard to blood proteins. Several years ago some preliminary work was done by Mrs. Lois Koenig at our laboratory, using electrophoretic procedures to determine the changes in the blood globulins. In this particular work the investigator showed a rather nice correlation between the protein changes in the blood of arthritic swine and those in the blood of the human arthritic patient. In arthritic swine the albumen content fell to about two-thirds of normal, while the levels of beta- and gamma-globulin rose to 50 and 30 per cent. above normal. A 10 per cent. increase in the concentration of fibrinogen was also observed.

These findings may serve to illustrate another of the many parallels between the disease in swine and rheumatoid disease in man.

Chemical Changes in Connective Tissue resulting from Injury. By Anna-Mae P. A. Luft, and R. $\mathbf{H}$. Pearce, London, Ont., Canada.*

The morphological changes in the tissues affected by the rheumatic diseases resemble in many respects, the inflammatory response that follows local injury to connective tissue. Accordingly, a study of the chemical changes that followed the production of a necrotizing lesion in the skin was undertaken with the hope of elucidating the pathological process associated with the "rheumatic" diseases.

Male Sprague-Dawley rats were injected intracutaneously with $0.5 \mathrm{ml}$. 1 per cent. croton oil in corn oil. At intervals following the injection, the injected and uninjected control skin was analysed by a method for the separation of normal rat skin into ground substance, interfibrillar cement, and collagen. Parallel histological studies were made.

Fibrinoid degeneration involved a marked fall in the hydroxyproline of the collagen fraction with little change in its glycoprotein content. Simultaneously, the free acid mucopolysaccharide and mucoprotein of the extrafibrillar fractions increased. The initiation of repair was associated with a marked systemic rise in the glycoprotein content of the collagen and a fall in the extrafibrillar carbohydrate and hydroxyproline. The hydroxyproline content of the collagen increased as it matured.

* This investigation was supported by the Canadian Arthritis and
Rheumatism Society and the Division of Medical Research of the Rheumatism Society and the Division
National Research Council of Canada. 
Discussion.-Dr. Thomas G. Kantor (New York, $N . Y$.): Did the determination of the factor of dry weight take into account the large influx of inflammatory cell material in these lesions? This factor would tend to give abnormally low values of hexosamine and collagen in lesions with large amounts of cells as opposed to those with smaller numbers when related to dry weight.

Dr. Pearce: The dry weights included the solid materials from any cells that entered the tissue. As you can appreciate, the measurement of the material contributed by the cells would be extremely difficult. We hope in future to perform analyses upon a known area of skin so that results may be expressed as changes per unit area rather than in terms of dry weight, as here. Certainly the contribution of the cells may be significant and should be assessed, if possible, in future experiments.

Dr. KARL MeYer (New York, N.Y.): I want to give a warning against the adoption of this classification, especially so far as mucoid is concerned. We have isolated this substance in the polysaccharide called keratin sulphate which contains both hexosamine and hexose and is a polysaccharide, but would not follow the classification adopted here.

Secondly, in this type of extraction you find terrific interactions of the proteins with polysaccharides and of the polysaccharides with themselves; I would rather see some isolation of definitive compounds, if possible, before drawing this conclusion that there is, especially with the development of reticulin, mucoid and not polysaccharide involvement.

Dr. Pearce: There is no doubt that the materials which we have called, for simplicity's sake, "mucoid" could actually be keratosulphate or some similar compound. If a keratosulphate-like compound were bound covalently to protein, the product would resemble the mucoids of connective tissues. I attempted to give a clear definition of the type of chemical change that would be attributed to "mucoid", "acid mucopolysaccharide", and so on. Such terminology serves primarily as an aid in discussion. Thus the validity of the conclusions we have drawn is limited by the uncertainty regarding the chemical nature of the compounds involved in the biological processes.

Experimental and Clinical Studies of a Heparin-Precipitable Fraction of Fibrinogen. By RICHARD T. SMITH, Minneapolis, Minn.

A catastrophe of widespread haemorrhage and necrosis, the generalized Shwartzman reaction, occurs regularly after either two appropriately spaced intravenous injections of Gram-negative bacterial endotoxin or a single injection of endotoxin in combination with certain high molecular weight acidic polymers, such as dextran sulphate. An explanation for these lesions has been found in extensive occlusion of small vessels by hyaline material with staining characteristics of fibrinoid. This fibrinoid material has further been shown to consist in part of fibrinogen, probably derived from the circulating blood. Attempts were therefore made to identify an alteration of circulating fibrinogen occurring after injection of endotoxin which might have staining characteristics and other properties of fibrinoid. As a result of such studies a qualitative change in circulating fibrinogen of rabbits manifested by cold-precipitation in the presence of heparin, was found to occur as a regular response to a single intravenous injection of endotoxin.

Histopathologically, vascular fibrinoid lesions of the generalized Shwartzman reaction in animals resemble strikingly those found in certain human diseases, such as lupus erythematosus, polyarteritis nodosa, acute fulminant rheumatic fever, and fulminant rheumatoid arthritis. It was of interest therefore to examine the the plasma of patients with these diseases for the presence of a similar fraction. In the plasma of severely ill patients with all of the diseases mentioned, and also in those with severe bacterial meningitis, endocarditis, and disseminated malignancy, a cold-insoluble, heparinprecipitable fraction was found in large amounts.

Extension of these studies utilizing a semiquantitative technique has shown that small amounts of the fraction are present in normal human plasma, the mean value being $0 \cdot 13 \mathrm{~g}$. per cent. Levels in severely ill patients ranged from 0.3 to $0.8 \mathrm{~g}$. per cent. A few children with acute rheumatic fever had levels as high as $1.4 \mathrm{~g}$. per cent. Serial studies of this fraction during the entire course of rheumatic fever, rheumatoid arthritis, acute bacterial infections, and other diseases have indicated that initially high levels return rapidly to normal upon spontaneous inactivation of the disease or as a result of steroid or antibiotic therapy. Whereas in normal persons the ratio between heparin-precipitable fraction and clottable fibrinogen was in the range of $0 \cdot 3-0 \cdot 6$, in these acutely ill patients, this ratio was most often greater than unity. Correlations were made between the levels of this fraction and fibrinogen, sedimentation rate, C-reactive protein, mucoprotein, and electrophoretically measured plasma protein fractions.

Chemical studies of the fraction indicate that it is closely related to fibrinogen, in its absence from serum, partial clottability, and electrophoretic mobility, but differs from normal fibrinogen in its insolubility at $4^{\circ} \mathrm{C}$. in combination with heparin and other similarly charged polymers. Solubility at this temperature is influenced markedly by $p \mathrm{H}$, ionic strength, and the presence of calcium or magnesium ions. Detailed studies of solubility, electrophoretic mobility, sedimentation characteristics, and end-group patterns are in progress in an attempt to determine the exact relation of this fraction to fibrinogen.

The data available are consistent with the conclusion that the heparin-precipitable fraction represents a qualitative change of fibrinogen which increases as a reflection of the presence of inflammatory disease. The possible relation of this fraction to fibrinoid deposits in human disease is as yet unknown, but currently under study.

Discussion.-DR. JOSEPH E. WARREN (Pittsburgh, Pa): This paper calls to mind the report by Abrams in Great Britain of the apparent resistance of rheumatic patients to the anticoagulant action of heparin in vivo. Perhaps the fibrinogen fraction which precipitates with heparin may also be the factor which interferes with the anticoagulant action in rheumatic patients.

DR. SMITH: I am aware of Abrams' work and find it of great interest. I have tried to perfect their technique 
in my laboratory, but without success as yet. Therefore, I have no comment to make except that their findings may have some relationship to this.

Isolation of Hyaluronic Acid from Synovial Fluid by Electroconvection. By Saul Roseman, Donald R. Watson, Ivan F. Duff, and William D. Robinson, Ann Arbor, Mich.

Electroconvection has been used in attempts to isolate undegraded hyaluronic acid (HA) or its protein complex from bovine and pooled human synovial fluid (SF). With the $p \mathrm{H} 7$ and temperature below $1^{\circ} \mathrm{C}$., a portion of the HA acted in the expected manner and was transferred from the upper to the lower reservoir. An appreciable fraction of the $\mathrm{HA}$ was deposited on the channel closest to the anode in the form of a gel $\left(G_{1}\right)$. From 60 to 70 per cent. of the total HA could be recovered as $G_{1}$ when the $S F$ was introduced in a continuous manner into the bottom reservoir and forced against the convection currents into the channel. The remaining HA was found in the lower reservoir at the end of the experiment. A portion of the soluble $\mathrm{HA}$ could be deposited by subjecting the reservoir solution to electroconvection. When $\mathrm{G}_{1}$ was dissolved in buffer and treated again in the same manner, it yielded a gel $\left(\mathrm{G}_{2}\right)$. Repeating the procedure once more yielded $G_{3}$. Analysis showed that the ratio of $\mathrm{mg}$. protein $/ \mathrm{mg}$. HA in these materials was as follows: dialysed $\mathrm{SF} 33 \cdot 5 ; \mathrm{G}_{1} 1 \cdot 8$; $\mathrm{G}_{2} \mathbf{0} \cdot 25 ; \mathrm{G}_{3} \mathbf{0} \cdot \mathbf{1 3}$. The purification factor of $\mathrm{HA}$ with respect to protein is therefore about 258 in $G_{3}$ compared with SF. Preliminary viscosity studies indicate that the gels and SF exhibit approximately the same relative viscosities at equal concentrations of HA.

It was of interest to find that heparin and sodium chondroitin sulphate did not deposit as gels under the conditions described above. After chondroitin sulphate was added to synovial fluid, the $H A$ was isolated $\left(G_{2}\right)$ with no detectable chondroitin sulphate contamination.

Discussion.-DR. Morris ZIFF (New York, N.Y.): The viscosity of the hyaluronic preparations seems to be independent of how much protein is present in the preparation. Do you feel then that protein binding has no influence on the viscosity of the hyaluronic acid in the synovial fluid?

DR. Roseman: It has been known for a long time and other workers have established that the viscosity of joint fluid, despite its high protein concentration, is almost completely dependent upon the polysaccharides. I also remember that Drs. Ropes and Bauer's group was involved in this some time ago. The addition of trypsin to the fluid does not result in an appreciable decrease in viscosity. The addition of hyaluronidase results in an immediate and very sharp decline of viscosity to the viscosity of serum, so that it would appear as though the protein is not too significant.

DR. MoRrIS ZIFF: What about the protein binding? Do you think there is actual binding or not?

DR. Roseman: This is quite another matter. I cannot say that we agree with Ogston, or Blix, or Meyer. We have gone down to a preparation which is roughly 10 per cent. protein, and exhibits the same viscosity as our other preparations of much higher protein content. If one wanted to take the data of Ogston at face value, one would have to conclude that these results do not support his contention. But we should wait a little longer and see whether we can get a preparation free of protein by our best analytical techniques; if it retains the same viscosity we should have to conclude that the viscosity of joint fluid is dependent upon the polysaccharide alone.

Dr. R. H. Pearce (London, Ont., Canada): Do you feel that your technique might have selected from the synovial fluid the hyaluronate that was undegraded and uncombined with protein? If this were the case, your finding that the isolated hyaluronate was undegraded and protein-free would signify only that a part of the hyaluronate of synovial fluid was in this state.

DR. Roseman: We do not recover 100 per cent. of the polysaccharide that goes in. The soluble fraction is always down in the lower reservoir. If you re-run the soluble component you recover an appreciable yield of gel, the same type of yield as is obtained with the whole fluid, i.e. 60 per cent. We have not yet repeatedly electroconvected the lower reservoir material.

Assuming there may be several types of hyaluronate, it is interesting to note that in just a single experiment chondroitin sulphate of molecular weight of 17,000 yielded no gel. When an aqueous extract of fresh cartilage was made, following the technique of Schubert and co-workers, we did obtain a gel which was rich in chondroitin sulphate; so I think we are selecting the protein polysaccharide components, not the polysaccharide alone.

The important concept concerning this protein complex is whether it is ionic or non-ionic. Dr. Meyer showed a long time ago that you could precipitate the polysaccharide with protein at the right $p \mathrm{H}$, and you can obviously get a complex of the ionic or salt type. He also pointed out that this might exist in synovial fluid, but this is not at all the type of complex dealt with by Ogston's group.

Dr. Ward Pigman (Birmingham, Ala): As Dr. Roseman knows, this problem is not quite as simple as it might appear on the surface. For example, we have just the elementary problem of measuring viscosity with such materials and such systems. Frequently these materials are not truly viscous, and do not obey the laws for truly viscous solutions, so that one's results depend upon the particular apparatus and method used. The question is particularly complicated in dealing with the concentrations in synovial fluid, because the ideal viscosity will be demonstrated only in very dilute solutions.

This does not reflect on Dr. Roseman's work, but we have to keep our minds open. We have not decided yet whether a complex is formed between protein and hyaluronic acid or other materials in the actual synovial fluid.

DR. Roseman: This does reflect-I think rightly-on the data reported. When the materials are not Newtonian, they do not behave in an ideal manner. We are only talking about relative viscosities and we have run all the samples through the same viscosimeter under the same conditions so that we can plot them on the same curve. I make no claims concerning the absolute or intrinsic viscosity.

Dr. Ward Pigman: I think it might be as well to drop 
the term "viscosity" in these kinds of measurements. We are now involved in measuring or attempting to measure something which you might call "viscosity", but we are planning to call it "flow rate", or something like that.

DR. Roseman: You are now, aren't you, rewriting your book, and as soon as you come out with a new term I shall be very happy to adopt it.

Dr. Karl MeYer (New York, N.Y.): In this discussion it is not a matter of whether there are, under certain circumstances, complexes with protein. The question is whether the physical properties of normal synovial fluid or of any synovial fluid are determined by hyaluronic acid or by a complex of definitive nature, as Ogston has said.

I think the experiments which Dr. Roseman described answer this in the negative, because Ogston has said, using the same or similar criteria to those of Dr. Roseman, that the most sensitive physical property was the viscosity. This is a perfectly justifiable term to use; whether it is known as a butonium or non-butonium type of viscosity, it is still viscosity.

Dr. Ogston, who is an extremely capable physical chemist, has come to the conclusion that the physical properties of synovial fluid are determined by a protein complex containing at least 25 per cent. protein. Now, by a rough calculation from Dr. Roseman's figures, the protein concentration is in the order of 10 per cent. Is that right?

Dr. Roseman: Yes.

DR. KarL MEYer: This in itself would abolish the argument which Ogston used. Furthermore, Dr. Blumberg in our laboratory has measured viscosity, not the relative but the absolute viscosity, one of the reduced viscosities, and by all our criteria the hyaluronic acid (which we isolated not from synovial fluid, but from streptococcus and from a human tumour) had exactly the same properties, not only in viscosity but in all physical characteristics, as Ogston ascribed to the protein complex.

The protein content of our material was less than 0.3 per cent. protein.

These experiments clearly show that the physical properties of hyaluronic acid solutions are determined by the hyaluronic acid itself and not by any complex whatsoever of hyaluronic acid with protein.

Dr. Marian W. Ropes (Boston, Mass.): I think it is important to describe the type of viscosity being measured because I feel, with Dr. Pigman, that we cannot use the general term "viscosity". Ogston found the biggest change in viscosity measurements as a change in anomalous viscosity, the variation of viscosity with different flow rates.

Experiments done in the presence of buffer do not necessarily prove whether or not there is a combination of protein and polysaccharide in the original or native state. As soon as the fluid or material is put in any buffer of any type, that it is no longer in its native state has been one of the difficulties in solving the problem which has been presented under so many different facets over the years.

DR. Roseman: It seems to me that we have left the native state as soon as we take the sample out of the joint.

Dr. Marian W. Ropes: That is true.

DR. Roseman: There is always that limitation. We always have to work within the limitations imposed by our methods. So far as we know, this is the most sensitive (or the least vigorous) method for isolation.

Concerning the viscosity question, all we can do and all we are interested in doing at the moment is to determine that the preparations, under the same conditions as the initial fluid, exhibit the same viscosity, using the same viscosimeter.

Concerning the problem of the buffer, I feel that the viscosity of the joint fluid as it is withdrawn from the animal does not change markedly when it is dialysed against the buffer.

Dr. Ward Pigman: In the first place, as Dr. Ropes has shown, salts have a tremendous influence on the viscosities of these types of compounds. I do not know how you take this factor into account.

The other thing is that very few people are dealing with normal fluid; most investigators have worked with arthritic joint fluid or cattle fluid, which are of a very much lower viscosity than normal fluid. The normal picture is quite different from that for arthritics. What we want to know in talking about a combination of protein and hyaluronic acid is how it appears in the normal fluid, and only secondarily what happens in the synovial fluid in the arthritic joint.

Dr. Roseman: I hope Dr. Pigman can send us some normal fluids to run through, for we are having difficulty getting enough.

Chromatographic Separation of $\mathbf{S}^{35}$-labelled Materials from Cartilage and Bone of Suckling Rats following Administration of Sodium Sulphate-S ${ }^{35}$. By D. DZIEWIATKOWSKI, N. DiFERRANTE, and F. BRONNER, * New York, N.Y.

Chondroitin sulphate is known to be present in cartilage and its presence in bone has been suspected. The suggestion has been made that this polysaccharide plays a role in endochondral ossification. Recently the feasibility of using $\mathrm{S}^{35}$-labelled sulphate for the study of the metabolism of chondroitin sulphate was demonstrated and the possible presence of other sulphated materials was suggested. A chromatographic separation of sulphated components in cartilage and bone was therefore undertaken.

Following the administration of $100 \mu \mathrm{c}$. $\mathrm{S}^{35}$-sulphate intraperitoneally to each of ten rats on their 7 th day of life, the animals were sacrificed in pairs at certain intervals. After dissection the epiphyses of the tibiae and femora were separated from the diaphyses, which were then freed of bone marrow. Alkaline extracts were prepared and, following adjustment of $p \mathrm{H}$ with acetic acid to $6 \cdot 5-6 \cdot 7$, a portion of each extract was chromatographed on a column of Dowex-2. Solutions of increasing chloride concentration were used to elute the $\mathrm{S}^{35}$-containing materials. Extracts of the epiphyses contained about 90 per cent. of the total sulphur-35 in the tissues; an average of 75 per cent. of the activity was extracted in the case of the diaphyses. Recovery from the columns in all cases was nearly 100 per cent.

Six peaks of radioactivity were demonstrated in the chromatograms. The sulphate-35 in one peak was

- Fellow of Helen Hay Whitney Foundation, 1954-55; Fellow of the Arthritis and Rheumatism Foundation. 
associated with inorganic sulphate, in another with material which behaved like chondroitin sulphate. Glucuronic acid and hexosamine were detected in the remaining four peaks.

The sulphur-35 activity associated with the inorganic sulphate peak diminished rapidly with time after administration of the $\mathrm{S}^{35}$-sulphate. The concentration of sulphur-35 in each of the other peaks increased rapidly up to about the 24th hour; thereafter it decreased slowly, but at a rate that was different peak to peak.

\section{Degenerative Joint Disease in Obese and Non-Obese Mice} of Strain $\mathbf{Y}^{\prime}$. By MARTIN Silberberg and Ruth Silberberg, St. Louis, Mo.

In previous experiments carried out in mice of various strains, articular ageing and the evolution of degenerative joint disease were found to be influenced by nutritional factors: A high-calorie high-fat diet accelerated articular ageing and increased the incidence of degenerative joint disease, while underfeeding delayed these changes. Under the influence of a high-fat diet overweight occurred in mice of some strains. However, there was no definite correlation between weight increase and the incidence of degenerative joint disease, and additional investigations along these lines seemed indicated. Mice of strain YBR/Wi present suitable test material to analyse further the effect of obesity on degenerative joint disease. This strain comprises two types of individuals which differ, as far as is known, in regard to only one gene. One type possesses a gene $Y^{\prime}$, the other type does not possess this gene. Bearers of the $Y^{\prime}$ gene are characterized by yellow coat colour and by a tendency to develop obesity, when fed enriched diets. Animals not possessing this gene are grey-coated and do not become obese, when kept on such dietary regimens. Grey-coated and yellowcoated mice of both sexes were fed through life $(a)$ a stock diet, (b) a high-fat diet, or (c) a high-carbohydrate diet respectively.

Diets enriched in animal fat may accelerate the onset and increase the incidence of degenerative joint disease irrespective of obesity. Excessive obesity is a contributory factor in the pathogenesis of osteo-arthritis. Findings in the pancreas, the uterus, and the bony diaphyses suggest that endocrine disturbances exist in YBR mice and that these metabolic disturbances may, in turn, play an aetiological role in the pathogenesis of degenerative joint disease in these mice.

Discussion.-Dr. F. Bronner (New York, N.Y.): Did you have an opportunity to study the sections which would reveal possible parathyroid enlargement in these mice?

Dr. Silberberg: We found no changes in the parathyroids in these mice.

Dr. IRVIN Stein (Philadelphia, Pa): In your sections, what was the problem in regard to the capillaries? I was interested in whether you found sections of capillary hypertrophy.

Dr. Silberberg: The criteria were the same as those postulated for humans. Therefore, we think we are safe in considering the disease in the mouse as an analogue of human degenerative joint disease.
Dr. Evan Calkins (Boston, Mass.): Did I understand correctly that 60 per cent. of the yellow mice had developed amyloidosis?

Dr. Silberberg: Yes, in both grey and yellow mice.

Dr. Evan CalKins: Did this high percentage of grey and yellow mice develop amyloidosis?

Dr. SILBERBERG: Yes, irrespective of sex and irrespective of diet.

Dr. Evan Calkins: Have other strains of mice that you may have observed shown this incidence of amyloidosis?

Dr. Silberberg: No, in our other strains of mice we have rarely seen amyloidosis. In the $\mathrm{Y}^{\prime}$ mice, there was a considerable amount of amyloid deposited. In mice of some other strains spontaneous amyloidosis occurs; for instance in Strain A it is associated with pyelonephritis, and also reaches a very high incidence.

Dr. Evan CalKINs: I was interested because we have tried to produce amyloidosis in mice by various measures, and in various strains, and we have found a very low incidence.

DR. SILBERBERG: I think, in the National Institute of Cancer at Bethesda, 10 or 12 years ago, this very high incidence of spontaneous amyloidosis was observed in mice of Strain A.

Studies on the Diurnal Pattern of Urinary 17-Hydroxycorticoid and 17-Ketosteroid Excretion in Patients with Rheumatoid Arthritis. By S. Richardson HILl, JR., Howard L. Holley, Willard R. Starnes, and Lester L. HibBetT, Birmingham, Ala.

Experimental evidence would indicate that adrenal cortical function is normal in the majority of patients with rheumatoid arthritis, although there are theoretical objections to the contrary. Because of the availability of more precise techniques for measuring adrenal cortical secretory activity and because of the accumulating evidence for a fairly consistent pattern of steroid excretion in normal subjects, this study of adrenal cortical function in patients with rheumatoid arthritis was undertaken.

Four groups of subjects were studied:

(1) Nineteen ambulatory normal male dental students;

(2) Five hospitalized young male patients with little physiological effect from various diseases;

(3) Six hospitalized male patients with active rheumatoid arthritis;

(4) Five hospitalized male patients of comparable age with non-rheumatic chronic diseases.

Urine specimens were collected from 7 a.m. to 1 p.m. and 1 p.m. to 7 p.m., and one specimen from 7 p.m. to 7 a.m. for one or more days on all subjects for determination of the total 17-hydroxycorticosteroid and 17-ketosteroid content.

There is no appreciable effect of hospitalization alone on the total 24-hr urinary output of 17-hydroxycorticosteroids or of 17-ketosteroids. The characteristic morning increase in steroid output observed in normal subjects is much less striking in hospitalized patients, resulting in a flattened diurnal excretory pattern. Hospitalized patients with rheumatoid arthritis and patients 
with non-rheumatic chronic diseases have a similarly flattened diurnal steroid excretory pattern. The total 24-hr urinary output of 17-hydroxycorticosteroids is lower in patients with rheumatoid arthritis and with non-rheumatic chronic diseases than in the other two groups of subjects studied.

The ratio of 17-hydroxycorticoids to 17 -ketosteroids is lower in the patients with rheumatoid arthritis than in the other groups.

Discussion.-DR. Joseph E. WARRen (Pittsburgh, Pa): We have also been conducting diurnal corticoid studies, but prefer to depend on plasma corticoid assays. On a chart summarizing our pertinent data the vertical scale represents concentration of hydrocortisone in plasma, and the horizontal scale shows the 24 hours starting at 8 p.m. Observations were made every $3 \frac{1}{2}$ hours. The average levels were plotted for nine patients with rheumatoid arthritis and nine comparable controls. The patients were ambulatory, showing minimal to moderate activity of the rheumatic process; none had been on cortisone, and aspirin was omitted during the study. Peak levels occur in the middle of the chart and represent the assays at 7 a.m. before rising from bed and very shortly after awakening. The chart shows a definite diurnal variation in the plasma levels in both groups, the peak levels being similar in time and degree, and there is also a tendency for the levels at $3.30 \mathrm{a} . \mathrm{m}$. to be higher in the rheumatoid patients than in the controls. This might well account for some of the flattening of the urinary excretion levels since it reduces the slope of the subsequent rise to the morning peak. The cause of this early morning difference in plasma levels will require further study.

DR. Hildegard Wilson (Bethesda, Md): In our laboratory at New York University we have also been analysing urinary steroids in two male subjects with rheumatoid arthritis. For comparison we used a pool of urine from healthy young men, worked up by identical procedures.

We made detailed analyses using paper chromatographic separation into twelve fractions, then applying a battery of corticosteroid assays to each eluate, and finally carrying out further procedures for purification and characterization of steroids.

In agreement with Dr. Hill's findings on hospitalized patients, one of our rheumatoid subjects was well below the controls in his content of polar corticosteroids, as measured by the formaldehydogenic and chromic-acidketosteroid assays. These polar compounds would account for most of the titre obtained by the Porter-Silber reaction which Dr. Hill used.

Our assays also determine the less polar corticosteroids, and the titres of these substances, in contrast, were elevated to about twice the normal in both the rheumatoid subjects. As a consequence, both titres of total corticosteroids were above those of the normal controls.

In a search for the metabolites responsible for these differences, identification procedures showed two polar metabolites, Compound $\mathrm{E}$ and Compound tetrahydro $\mathrm{E}$, to be present in the normal urine but absent in the one rheumatoid so studied. Moreover, five less polar metabolites were present in the patient's urine, but absent, or found only in traces, in the controls.

When ACTH was given to the rheumatoid subject, Compounds E, F, tetrahydro E, and tetrahydro F were identified in his urine. Some of the "abnormal" less polar compounds diminished or disappeared, while others remained.

These observations suggest that the "steroid abnormality" in this subject was related to the effectiveness of his endogenous ACTH rather than to any inability of his adrenal cortex to make the normal complement of hormones. Without extra ACTH the biosynthetic reactions in his adrenal cortex seem to have produced less of the fully hydroxylated hormones, and more intermediates of lower oxygenation. Administration of exogenous ACTH changed these processes towards normal. Further studies are required to see whether or not this picture is characteristic of rheumatoid arthritis.

Dr. Hill: In terms of theoretical knowledge to be gained, I think that Dr. Wilson's studies represent the most fruitful approach to the subject of any that are now being employed. The absolute determination of the qualitative pattern of adrenal cortical secretion might once and for all give us the answer, in humans, to the question that has been raised by Dr. Hans Selye regarding the abnormal ratios of phlogistic to anti-phlogistic hormones in certain "rheumatic disease states" in animals. Dr. Wilson's experience on one patient should certainly be extended.

Dr. Robert S. Howell (Miami, Fa): The diurnal variation may also reflect the glomerulo-filtration rate, which is known to affect the rate of excretion of hydroxycorticosteroid.

DR. HiLl: Thorn and Laidlaw (1954) have shown that the characteristic diurnal pattern of adrenal cortical secretion persists in normal subjects despite forced inactivity in bed for 24 hours, a reversal of the normal working schedule, 24-hour starvation and alteration in fluid intake sufficient to induce an overnight polyuria. In considering the mechanism by which the diurnal variation of corticosteroid output is controlled, it is of interest to note that the urinary excretion of 17-hydroxycorticoids in patients with Addison's disease receiving maintenance doses of cortisone or hydrocortisone by continuous intravenous infusion at a constant rate, contrasts sharply with that seen in normal individuals. This suggests that this cyclical rhythm does not reflect variation in the intermediary metabolism or excretion of adrenal cortical steroids, but rather reflects diurnal swings in pituitaryadrenal or hypothalamic-pituitary-adrenal secretory function.

Dr. Evan Calkins (Boston, Mass.): While we are on the subject of diurnal variations, I should like to point out that Dr. Daniel Bachman, in our laboratory, in some preliminary studies, has shown that the normal diurnal variation in urinary chloride excretion appears to be absent, or reversed, in patients with active rheumatoid arthritis.

Dr. Vincent C. Kelley (Salt Lake City, Utah): In agreement with Dr. Wilson's comments, I feel that one should take care not to draw too sweeping conclusions regarding the normality of adrenal function on the basis of 17-ketosteroid and 17-hydroxycorticosteroid excretion. We are finding in many conditions now that alterations in the pathways of steroidogenesis, resulting in different end-products and different concentrations of various intermediates of steroidogenesis, may be of more significance than the total amount of 17-hydroxycorticosteroid or 17-ketosteroid groups excreted. 
We must remember that there are many different methods for measuring 17-ketosteroids and several for 17-hydroxycorticosteroids, and that with different methods the results are different. In view of the somewhat elevated 17-ketosteroid excretions, it is worth recalling that several workers have indicated that the excretion of 17-ketosteroids is decreased in rheumatoid arthritis.

In our studies in children with juvenile rheumatoid arthritis, the plasma levels of 17-hydroxycorticosteroids, done by the technique of Nelson and Samuels (1952), have been low, whereas the urinary excretion of these steroids has been within normal limits. The excretion of "17ketogenic steroids" has been shown to be low in rheumatoid arthritis; initially this was reported as being about 40 per cent. lower than normal, but this figure has now been revised. Appleby and Norymberski (1955) studied the 21-deoxyketols and concluded that these were normal in patients with rheumatoid arthritis; but in the only very acute case of rheumatoid arthritis in their series the 21deoxyketols were approximately twice as high as in any other patient in the entire series.

It would appear that there is considerable evidence suggestive of abnormal adrenal function in patients with rheumatoid arthritis, but no one is in a position to define the exact status of pituitary adrenal function in such patients, so that many studies such as Dr. Hill's are needed to clarify this problem.

DR. HILl: The total 17-hydroxycorticosteroids were determined by a modification of the method of Reddy, Jenkins, and Thorn (Reddy, 1954). This is a butanol extraction method with a Porter-Silber colour reaction (Porter and Silber, 1950). The 17-ketosteroids were extracted by a modification of the method of Drekter and others (1952), and the colorimetry was performed as in the procedure of Holtorff and Koch (1940).

Using these methods in our laboratory, we have been able to obtain very consistent and reproducible results.

As to the question of normal adrenal cortical function in patients with rheumatoid arthritis, I am of course speaking in terms of the techniques employed in these studies-that is by measuring total 17-hydroxycorticosteroids and 17-ketosteroids. I should not like to leave the impression that I think adrenal cortical function is either normal or abnormal in patients with rheumatoid arthritis. This subject is still open to investigation.

Many studies show a low degree of urinary 17-ketosteroids in patients with rheumatoid arthritis; there are, however, almost as many reports showing normal or increased levels of 17-ketosteroids.

Dr. William D. Robinson (Ann Arbor, Mich.): I should like to add my congratulations on this excellent work, and to add a word of warning with respect to its interpretation that is in no way intended as a criticism. We must be careful in interpreting the pattern of steroid excretion in the urine as necessarily representing what the adrenal is releasing into the blood. Information on what happens to these steroids between the time they leave the adrenal and the time they are determined in the urine is extremely important. Conn and others (1954) have developed a test in which the pattern of excretion of 17-ketosteroids and 17-hydroxycorticosteroids is determined after test doses of hydrocortisone, or, preferably, Compound S. Dr. Duff and others from our laboratory have applied this test to patients with rheumatic diseases and found clear-cut differences in the proportions of such steroids which are excreted as 17-ketosteroids and as 11- or 17-hydroxycorticosteroids. We must be careful in this very complicated problem to distinguish between what may be produced by the adrenal in terms of abnormal steroid production and what may actually constitute an abnormal metabolism of the steroids before they appear in the urine.

DR. HILl: I agree that we cannot say that the changes found in steroid levels represent changes in adrenal cortical function. It is entirely possible that the differences noted represent alteration in steroid metabolism rather than in adrenal cortical secretory activity. Indeed, such alterations in steroid metabolism have been shown to occur by the use of radio-actively tagged hydrocortisone.

\section{REFERENCES}

Appleby, J. I., and Norymberski, J. K. (1955). Annals of the Rheumatic Diseases, 14, 172 .

Conn, J. W., Fajans, S. S., Louis, L. H., and Seltzer, H. S. (1954) J. Med., 43, 79 .

Drekter, I. J., Heisler, A., Scism, G. R., Stern, S., Pearson, S., and McGavack, T. H. (1952). J. clin. Endocrinol., 12, 55.

Holtorff, A. F., and Koch, F. C. (1940). J. biol. Chem., 135, 377.

Porter, C. C., and Silber, R. H. (1950). Ibid., 185, 201.

Reddy, W. J. (1954). Metabolism, 3, 489.

Thorn, G. W., and Laidlaw, J. C. (1954). Trans. Amer. clin. climatol. Ass., 65, 179 .

Influence of Salicylates on the Pituitary-Adrenal System in Normal and Rheumatic Human Subjects. By Alan K. Done and Vincent C. Kelley, Salt Lake City, Utah.

Considerable indirect evidence has suggested that salicylates produce pituitary-adrenal stimulation and that this effect accounts, at least in part, for their antirheumatic properties. The present report deals with more direct observations on the effects of salicylate on the pituitary adrenal system, obtained by measurements of adrenal hormones in blood and urine. Plasma 17hydroxycorticosteroid (17-OHCS) concentrations were determined by the method of Nelson and Samuels (1952) and Eik-Nes, Nelson, and Samuels (1953); urinary 17-OHCS by the method of Glenn and Nelson (1953).

Non-rheumatic individuals with salicylate intoxication were found uniformly to have markedly elevated plasma 17-OHCS concentrations.

Normal human subjects given salicylates in usual therapeutic doses failed to show consistent elevations in circulating levels of 17-OHCS. However, salicylate administration was accompanied by greater fluctuations in the plasma concentrations of these steroids than were found as normal diurnal variations. Both increases and decreases in steroid concentrations were significantly greater on days of salicylate administration than on control days. The urinary excretion of 17-ketosteroids was unchanged, while significant reduction in the urinary output of 17-OHCS was observed. These data are interpreted as suggesting a dual effect of salicylates on the pituitary-adrenal system:

(1) increased production of adrenal steroids due to pituitary stimulation;

(2) an increased rate of removal of these steroids from circulation by a means other than urinary excretion-(?utilization).

Additional evidence of this dual effect has been obtained by studies on the influence of salicylate on the half-life of exogenous hydrocortisone. Salicylate administration 
decreases the half-life (increases the rate of disappearance) of exogenous hydrocortisone and also produces an increased release of steroids by the adrenal cortex.

Rheumatic fever patients treated with salicylates uniformly showed no increase in circulating or urinary 17-OHCS levels. Indeed, in contrast to non-rheumatic individuals, even those rheumatics who developed severe salicylate intoxication failed to develop raised plasma 17-OHCS concentrations. Prolonged salicylate treatment for rheumatic fever resulted in a post-therapy diminution in 17-OHCS response to ACTH of a degree similar to that produced by prolonged cortisone therapy.

Discussion.-DR. S. Richardson Hill, JR. (Birmingham, Ala): What is the relationship between the free and the total, including both free and conjugated, urinary 17-hydroxycorticosteroid levels? The decreased urinary free 17-hydroxycorticosteroid levels reported following salicylates could be due to an increased conjugation of these steroids, and might not necessarily represent an increased rate of removal of these steroids from the circulation by a means other than urinary excretion.

DR. Done: Unfortunately I cannot give you any data at the present time. By "free", do you mean unconjugated?

\section{Dr. S. Richardson Hill: Yes.}

DR. DONE: We have had considerable difficulty in establishing a technique for determining conjugated corticosteroids, but we now have it worked out and expect to have some data shortly.

Dr. John N. Swanson (Toronto, Ont., Canada): At what time after the intravenous dose were these plasma levels measured? Some 4 years ago, working in Dr. Walter Bauer's group, I observed that the eosinophil count fell by more than 50 per cent. at the end of 5 hours after a large dose (4 g. or more) of sodium salicylate or aspirin had been administered orally. Doses of less than 4 gr. had no detectable effect, even though eosinophil counts were carried out hourly for 8 hours. If this fall is accepted as being secondary to adreno-corticoid liberation, it seems that it only occurs when large, nearly toxic, doses of salicylates are given, and may not therefore be due to the pharmacological action of the drug.

Dr. DONE: These levels were taken immediately before the next dose of salicylate was to be given. In most of these patients salicylate was given every 6 hours, so the sampling interval would be approximately $5 \frac{1}{2}$ to 6 hours after the administration of the previous dose.

Dr. Howard F. Polley (Rochester, Minn.): What was the plasma salicylate level in the patients with salicylate intoxication, and for how long had the symptoms of toxicity been present? Were the patients receiving any treatment for the salicylate toxicity?

DR. DONE: So far as duration of salicylate intoxication is concerned, we did not include patients in this group if they showed no more than the usual signs of intoxication one looks for in treatment of a rheumatic. In those included, the duration of administration leading to intoxication ranged from 2 hours to 4 days, and in each instance the symptoms were very severe. The salicylate levels ranged from 46 to $88 \mathrm{mg}$. per cent. The salicylate levels and symptomatology were comparable to those in the non-rheumatic individuals.
At the time when the samples were taken, the salicylate intoxication was not being treated.

Dr. Hildegard Wilson (Bethesda, Md): If salicylates exert their beneficial effects in rheumatic diseases because they increase adrenocortical activity, it seems to me that one would expect to see an increase in blood and urine steroids with a dosage of salicylates sufficient to produce a therapeutic result. I wonder whether you could give any idea of how the level of plasma 17-hydroxycorticoids on your dosage of salicylates compares with that resulting from the minimum amount of ACTH which produces the same beneficial effect. This might indicate whether or not the therapeutic results were both due to the same degree of adrenocortical stimulation.

DR. Done: I can speak only of the levels in intoxicated individuals since they are the only ones in whom we have seen them consistently elevated. The high steroid level observed in previously normal people with intoxication was approximately the same as we see after the intramuscular administration of $25 \mathrm{mg}$. of ACTHthat is, the response was essentially comparable. I have no data on the minimal dose of ACTH as compared with the minimal dose of salicylates which will produce this effect.

\section{REFERENCES}

Eik-Nes, K., Nelson, D. H., and Samuels, L. T. (1953). J. clin. Endocrinol., 13, 1280.

Glenn, E. M., and Nelson, D. H. (1953). Ibid., 13, 911

Nelson, D. H., and Samuels, L. T. (1952). Ibid., 12, 519.

Hip-Socket Arthroplasty. A Method of Surgical Treatment of Degenerative Arthritis of the Hip Joint. By Marshall R. URIST, Los Angeles, Calif.

This is a presentation of a procedure of arthroplasty developed from a study of the biomechanics of the hip joint, histophysiological observations of joint repair, and clinical experience with a hip-socket attached to the pelvis.

Special surgical instruments have been designed for implanting the socket through a postero-lateral approach. The hip-socket is a self-sustained lining for the acetabulum, made of vitallium, and is stable enough to allow motion immediately after the operation. The socket is open in the centre to contain fibrocartilage and mucinforming tissues as a source of lubrication inside the joint. It encloses only half of the head of the femur and thereby permits a wide range of motion.

The morphological and chemical structure of a pseudarthrosis and a functioning arthroplasty are so similar that it is reasonable to assume that basically the two conditions involve the same connective tissue cell process. Proliferation of fibrous connective tissue and fibrocartilage produce the earliest form of repair. Friction and motion between surfaces around the rim of the joint and in the acetabular fossa precipitates ground substance and produces fibrinoid, mucin, and mucinous fluid. During the first year, the surface of the head consists of dense fibrous tissue and fibrocartilage coated with fibrinoid. Further motion and pressure of weightbearing is necessary for 18 months to 2 or 3 years to produce differentiation of new hyalin-like cartilage from the underlying fibrocartilage. 
The joint surface formed from an arthroplasty after years of function resembles articular cartilage. It is not true articular cartilage but it can function as joint cartilage. It becomes increasingly like articular cartilage after a period of years of weight-bearing and after remodelling of the underlying spongiosa to produce an articular cortex of compact bone.

The immediate results obtained in 26 arthroplasties (including six bilateral), were sufficiently good to recommend the method for further trials. The long-term results in individual patients and various types of hip disease are, as yet, not known beyond 1 to two years in five cases, and one year or less in 21 cases. In circumstances favourable for arthroplasty, such as patients with malum coxae senilis, the results were immediate relief of pain, an increase of range of motion, and a stable joint. Hip-socket arthroplasty usually produced a greater range of rotation than cup arthroplasty. More flexion was also obtained; the theoretical explanation for this may be that there was a more normal de-rotation or unscrewing of the head of the femur during the swing phase of the joint motion.

Discussion.-Dr. Irvin SteIN (Philadelphia, Pa): I am particularly interested in Dr. Urist's work as an orthopaedic surgeon because he, to me, represents more than just a mechanic, since he has a scientific appreciation of underlying problems.

There are many unpredictables in arthroplasty that bother many men who do a great many of them, and I think he has taken care of one of them very well. This type of prosthesis, which is very different from those that are used commonly now, is more of an acetabular than a femoral head prosthesis, and for certain cases it appears to be really valuable.

Renal Involvement in Progressive Systemic Sclerosis (Diffuse Scleroderma). By Gerald P. Rodnan, George E. Schreiner, and Roger L. Black, Pittsburgh, Pa, Washington, D.C., and Bethesda, Md.

Progressive systemic sclerosis (diffuse scleroderma) is now recognized as a disorder capable of affecting many organ systems. While the clinical characteristics of cutaneous, gastro-intestinal, and cardio-pulmonary involvement have been well described, the incidence and and severity of renal disease have become more fully appreciated only recently. We have had the occasion to observe the development of abrupt fatal renal insufficiency in seven patients with progressive systemic sclerosis, and present the clinical and pathological features of these cases, together with the findings in one patient who developed only mild renal dysfunction, and one in whom the discovery of extensive renal lesions was not suspected from the clinical course.

When these cases are considered with others previously reported, it appears that renal involvement is of frequent occurrence and ominous significance in the natural history of progressive systemic sclerosis. The initial renal lesion is that of intimal sclerosis and hyperplasia involving primarily the interlobular arteries. When severe, these vessel changes lead to widespread focal cortical infarction and fibrinoid necrosis of the walls of afferent arterioles and glomerular loops. These present the clinical picture of fulminating cardiovascularrenal disease, characterized by severe hypertension, retinopathy, cardiac failure, convulsions, and rapidly progressive renal insufficiency.

In several reports the development of such renal damage has been attributed to the administration of ACTH or cortisone. It should be noted, however, that this complication had been observed before the introduction of these agents. Three patients in the present series had received neither ACTH nor cortisone. It is not yet clear, therefore, whether these hormones have induced such renal changes or accelerated the progression of already existing lesions.

Discussion.-Dr. William H. Kammerer (New York, $N$.Y.): What were the dosage ranges of hormones used in these patients?

DR. RoDNAN: Usually fairly moderate dosages, in the neighbourhood of 50 to $100 \mathrm{mg}$. cortisone daily. Some patients had received ACTH for only a few days, a matter of perhaps three or four injections in all.

DR. Theodore B. BAyles (Boston, Mass.): The thing that fascinates me in such patients is why you can follow them for 7,10 or 12 years and then within 3 months develop this picture of malignant hypertension and death. Prognostically speaking, it is very important to watch for such a development, though I do not know what you can do about it.

Not so many of our scleroderma patients died of renal failure, and during these long years of observation there has been very little evidence of renal disease. The mechanism of the terminal events is most interesting.

Experiences with a New Macroscopic Test for Systemic Lupus Erythematosus. By Stanley L. Lee, New York, N.Y.

The "L.E." cell phenomenon has proved a useful tool in the diagnosis of systemic lupus erythematosus, and may furnish a key to understanding the pathogenesis of this and possibly other rheumatic diseases. However, prolonged scanning of microscopic slides is tiresome and sometimes unsatisfactory in clinical work. Quantitation of the phenomenon is generally unsatisfactory, so that investigative work is hampered.

In the presence of high concentrations $(0 \cdot 2-0 \cdot 4$ $\mathrm{mg} . / \mathrm{ml}$.) quinacrine hydrochloride and a protein-rich medium (i.e. normal serum, bovine albumin) a suspension of human leucocytes (normal or leukaemic) undergoes spontaneous agglutination. This agglutination is inhibited by serum containing the L.E. cell factor (LECF). The leucocyte-agglutination inhibiting factor (LAIF) is identical with the L.E. cell factor. It is possible, by diluting an active serum progressively with normal serum or with serum albumin, to titrate the LAIF. Some sera exhibiting LECF activity fail to inhibit leucocyte agglutination; such sera almost always show some LAIF potency when compared with normal serum as diluents for a strong LAIF serum. False positive reactions have occurred, but, as more experience is gained, these seem to be less frequent; no serum which 
failed to produce L.E. cells has shown LAIF activity on two successive tests.

The test is easy to set up. As many as twenty tests have been done simultaneously, and reading is no more difficult than reading red cell agglutination tests. It is hoped that it may be useful in diagnosis and investigation.

Serum Complement Titres in the Differential Diagnosis of "Collagen Diseases" and their Aetiological Implication. By Ralph J. Wedgwood, Cleveland, Ohio.

Serum complement titres on over 300 samples from ninety patients with a variety of so-called "collagen diseases" indicate that the group can be divided into two distinct classes:

(1) Patients with acute post-infectious haemorrhagic glomerulonephritis, childhood nephrosis, and disseminated lupus erythematosus, who invariably have titres considerably below normal;

(2) Patients with rheumatoid arthritis or dermatomyositis during the active phase, who have elevated titres.

In addition, patients with chronic, subacute, or latent nephritis and with anaphylactoid purpura (HenochSchonlein's or Osler's syndrome), with or without renal involvement, tend to have titres higher than those of normal, healthy subjects. With induced or natural remissions, titres return towards normal ranges.

Thus the serum complement titre may be of assistance in the differential diagnosis of these diseases. Technically, the procedure is not complex, certainly no more difficult than the sheep cell differential agglutination titre; and it is readily adaptable to the routine of most laboratories performing serologic procedures.

The low complement titres in some of these diseases lead to interesting speculation. The relationship of complement to antigen-antibody interaction in vitro is well known; and there is experimental evidence suggesting that a similar interaction occurs in vivo in experimental serum sickness. While this could explain the low titres, the raised titres are more difficult to interpret. Evidence suggests that such titres occur following stress and can be induced by the injection of ACTH into an experimental animal.

Discussion.-DR. JosePH J. BunIM (Bethesda, Md): We are increasingly interested in finding a test or a pathological lesion that will help distinguish lupus erythematosus from rheumatoid arthritis and thus inform us which preceded the other, or whether one is a natural transition from the other. At the moment, I do not know of any single feature that is always present in one disease and not in the other, and this holds true now for the subcutaneous nodule and the sheep cell agglutination test, even when done by the Ziff euglobin modification. I wonder if Dr. Wedgwood has had any experience with this group of rheumatoid patients who also had the L.E. phenomenon so far as complementfixation testing was concerned.

DR. WeDGwOOD: The only patient we have had was the one with dermatomyositis, and in that case the complement-fixation test came within normal limits.
Clinical Behaviour of the Haemagglutination Test for Rheumatoid Arthritis. By GIDEON K. DEFOREST, and Paul L. Boisvert, New Haven, Conn.

This paper presents the results of a modification of the haemagglutination test in 135 patients with rheumatoid arthritis, and in a group of 219 controls. The method employs the settled pattern of sheep red cells for the determination of endpoint. A positive test is a serum titre of 8 units or more.

109 (95 per cent.) of the 115 patients with classical peripheral rheumatoid arthritis in Stages 1, 2, 3, and 4 had positive tests. Positive results were obtained in three of ten patients with rheumatoid spondylitis; in one of four cases of rheumatoid arthritis with psoriasis; and in three of six with juvenile rheumatoid arthritis.

Bunim has pointed out in a recent review that the haemagglutination test does not ordinarily become positive until 12 or 18 months after onset of the disease. This makes the test results in the early cases of note. Fourteen patients had tests during the first 6 months of their illness. Thirteen ( 92 per cent.) of these fourteen had positive tests - two within 2 months of the onset of symptoms.

Of further interest is the relation of the titre to disease activity. It is a matter of some controversy among investigators whether the titre of the test does vary with disease activity. Among the 135 patients with rheumatoid arthritis a distinct titre change was noted only in those individuals who had dramatic Grade 1 clinical remissions. This change occurred in thirteen of fifteen such patients. The test in seven of the thirteen eventually became negative.

The control groups of patients were chosen to place a maximum of stress on the selectivity of the test. Positive tests were obtained most frequently (6.5 per cent.) in the group of adults whose sera arrived at the streptococcus laboratory. The incidence of positive tests in the total control series is at this time less than 5 per cent.

Discussion.-A SPEAKER: What constitutes, in terms of dilution of the patient's serum, the lowest dilution which would be read as a positive test and what is the average dilution in most of your positives?

While working in the laboratory of Dr. George Heller, we were able to observe two individuals hospitalized for non-arthritic complaints, who developed their first 을 joint complaints while in the hospital. Serological tests of a somewhat different nature were positive within the $\frac{7}{0}$ first 12 hours of their disease. They have been followed subsequently and have gone on to deforming arthritis.

Dr. DEFOREST: Dr. Boisvert, who is the expert of this team, is here, and I will ask him to answer that question.

DR. BoISVERT: The titre that would be considered posi- $\omega$ tive is 8 units; that is, a $1: 8$ dilution of the patient's serum. This is the first tube of the test.

The usual degree of positivity or average titre for $\frac{}{\mathbb{D}}$ patients in the active stage will run, I think, about os 128 or 256 units. We do see patients with active rheumatoid arthritis with titres of 64 and even 2,048, but usually they are in the range of 128 to 512 .

Dr. Darrell C. Crain, Jr. (Washington, D.C.): $\frac{\stackrel{P}{\Phi}}{\stackrel{Q}{\Phi}}$ I should like to interject a somewhat negative response $\varrho$ 
to this test. Several years ago when it was first promulgated, I co-operated with Dr. Shultz, who was here at the Institute then, in testing 125 sera, and we obtained no correlation whatsoever between the diagnosis and the result of the test.

Recently, since the test was refined, a further group of bloods (I cannot give the exact number, though it was in excess of 30), were again submitted to a similar blindfold test and no correlation between the test and the disease was obtained.

All of us, of course, are looking for something of this sort, and the previous discussor, who mentioned several early cases which were positive and then went on to direct rheumatoid arthritis, has stated an important crux of this whole test. I think if Dr. de Forest's test is to mean anything as time goes on, it will be necessary to follow these early cases and to see if the negatives persist and 10 years later have no rheumatoid arthritis, and if the positives do so too.

DR. DEForest: We find that our negative tests occur most commonly in old-established cases. All our negative tests, except one, have occurred in individuals who had had the disease for many, many years and whose recent illness had been stabilized for periods of 6 months or longer.

How many of the early cases we miss, I do not know, but probably not many. I am sure some of those atypical cases whose tests were negative probably have rheumatoid arthritis, though diagnostic criteria as accepted to-day would exclude them.

DR. BOISVERT: Did I understand the statement correctly about the incidence of positive and negative tests-that there was no correlation between the tests and rheumatoid arthritis or other disease?

Dr. Darrell C. Crain: This was in the early stages of the test, some 4 or 5 years ago, and can probably be discounted now, but it caused us to make a bad start with the tests.

More recently, most of the discrepancies have been in positive cases which have not shown a positive test, and it may be, as Dr. de Forest says, that they are longstanding cases and that something else happens to make the test negative in chronic cases.

Relationship of the Polysaccharide Content of the Euglobulin Fraction in Rheumatoid Arthritis Serum to the Agglutination of Sensitized Sheep Erythrocytes. By Charley J. Smyth and Glenn M. Clark, Denver, Colo.

Recent evidence has indicated that the "euglobulin fraction" (Ziff, Brown, Badin, and McEwen, 1954) separated from the serum of patients with rheumatoid arthritis is highly specific in agglutinating sensitized sheep erythrocytes. It has also been reported (Shetlar, Payne, Bullock, Patrick, Hellbaum, and Ishmael, 1953) that the serum polysaccharides are raised in rheumatoid arthritis as well as in other diseases. The following experiments were performed in attempt to relate these two observations.

Estimation of the polysaccharide content of the euglobulin fraction of serum by the method of Shetlar, Foster, and Everett (1948) in 214 patients showed 103 cases in which the polysaccharide content was greater than
$25 \mathrm{mg}$. per cent. of original sera. In 74 of these cases the same fraction was found to agglutinate sensitized sheep erythrocytes at dilution greater than $1: 28$. Of the 111 cases in which the euglobulin polysaccharides were below $25 \mathrm{mg}$. per cent. of original serum, the haemagglutination test was positive in only four.

These findings indicate that, for haemagglutination to occur, some component which can be hydrolysed to produce a colour reaction with tryptophane must be present. However, in diseases other than rheumatoid arthritis polysaccharides, which are not components of compounds which agglutinate sensitized sheep cells, may be present in the euglobulin fraction in increased amounts.

Specific evidence that polysaccharide-containing components in rheumatoid serum are concerned in the sheep cell reaction was obtained from experiments in which it was demonstrated that when haemagglutination was produced by the euglobulin fraction, there was a significant decrease in the polysaccharide content of the supernatant fluid. It is assumed that this indicates the binding to the sensitized sheep cells of a polysaccharidecontaining component of the serum of patients with rheumatoid arthritis.

Discussion.-Dr. HaRry Bartfeld (New York, N. Y.): Do you feel that the polysaccharide itself would cause agglutination?

Dr. Clark: I feel that it would not, because we have occasionally been able to separate out the polysaccharide material by a chemical method, but have as yet been unable to reproduce the test with pure polysaccharides.

DR. HARRY BARTFELD: You probably know the work of Dr. Nanna Svartz in Sweden, who treated collagen with a bacterial enzyme and obtained an agglutination reaction with sheep cells.

Dr. Clark: Yes, Dr. Svartz has been able to identify several fractions which will agglutinate sheep cells. She was also able to demonstrate, to a member of our group who visited her laboratory last summer, separation of the fraction which causes agglutination in patients with lupus erythematosus.

Dr. Heller, in his laboratory, has at least two different fractions, and we have no idea about the relative specificity of each fraction. We have used this test because it is easy to do, and it has much simpler components than any of the more specific tests.

Also, in the euglobulin test, 3 per cent. sheep cells are used (more than in other tests), and we feel that any chemical binding which might occur, might be greater quantitatively with larger amounts of sheep cells.

DR. JohN H. VAughaN (Richmond, $\mathrm{Va}$ ): Could you see any gross difference between the cells agglutinated in the presence or absence of this polysaccharide? see any gross difference between the cells agglutinated I believe you indicated that you had as much as 45 micrograms of polysaccharide fixed by absorption. If this is the value you found, I think you should be able to see this amount of polysaccharide in or on the cells.

Dr. Clark: The cells show no white material, but, as we run our test, we take galactose and mannose and put it into the system to make our standard curve; 
we have found, as you have, that with high concentrations of galactose and mannose over the cells originally making the standard curve, the cells look more pink than red. This pink colour also develops when the cells are agglutinated by euglobin.

We run our sheep cell test to a titre of 4 so that, even in negative tests, we do not get the little button that Dr. deForest described, but a pinkish material at the bottom. We do not know that the pink colour develops from polysaccharide coating the sheep cell erythrocytes.

\section{REFERENCES}

Shetlar, M. R., Foster, J. V., and Everett, M. R. (1948). Proc. Soc. exp. Biol. (N.Y.), 67, 125 .

Payne, R. W., Bullock, J. A., Patrick, D. R., Hellbaum, A. A., and Ishmael, W. K. (1953). J. clin. Invest., 32, 1208.

Ziff, M., Brown, P., Badin, J., and McEwen, C. (1954), Bull. rheum. Dis., 5, No. 2, p. 75.

Some Characteristics of the Inhibitor System for the Sensitized Sheep Cell Agglutination. By R. R. Williams, S. S. Stone, J. Jenkins, R. L. Evans, and J. J. BuniM, Bethesda, Md.

The inhibitory activity of normal plasma has been reported by Heller to reside in Cohn Fraction II, and by Ziff in a euglobulin fraction precipitated at $p H \quad 5.8$ $\Gamma / 20.013$. The specific inhibitory activities varied widely in a number of Fraction II preparations. Lyophilized preparations were much more active than the 16 per cent. solutions available. Curtain electrophoresis at pH $3.2 \Gamma / 20.05$ revealed an activity maximum anodic side of the protein concentration maximum. 20 to 40-fold increases in activity resulted.

Inhibitory activity can be extracted from both rheumatoid and normal euglobulins at $p \mathrm{H} \quad 5 \cdot 8 \Gamma / 2 \quad 0.013$. Electrophoretic patterns of the extracts of rheumatoid euglobulins revealed a major component of $\gamma$ mobility and a smaller $\beta$ component. The original euglobulins contained components of $\alpha, \beta$ and $\gamma$ mobility, with a larger proportion of the $\beta$ component.

Repeated extraction of rheumatoid euglobulins sometimes reveals so much of the extractable component that equilibrium is re-established several times in a series of one-hour extractions. A small but easily measurable part of an inhibitory Fraction II preparation will bind to the rheumatoid euglobulins. The part bound appears to exert most of the inhibitory activity of this protein fraction.

It is postulated that any substance which can influence the dissociation equilibrium or bind to the active euglobulin component will exert inhibitory effects. Substances which, at $10^{-3}$ to $10^{-4}$ molar concentrations, have shown inhibitory activity include ureidosuccinic acid, 5-acetic acid hydantoin, glucosamine, and glycylglycine. Numerous amino acids, peptides, sugars, and related compounds were inactive.

Discussion.-A SPEAKER: Gamma globulin here is referred to as an inhibitor. As Dr. Heller has shown, the same gamma globulin which will inhibit these tests, when coated on a non-sensitized cell, is in itself agglutinated in the same way as all the amboceptor sensitized cells are agglutinated. It was the general feeling of our group that this did not constitute demonstration of an inhibition phenomenon; that, actually, the gamma which, as you have shown, inhibits the reaction can itself, when coated on a cell, be part of an agglutination test.

DR. Williams: It is quite possible that this is a competitive inhibition. However, the fact remains that we $\overrightarrow{\vec{F}}$ have measured the ratio of added normal gamma globulin to the gamma globulin calculated in the rheumatoid serum at various dilutions and measured the ratio of $\bar{c}$ added gamma globulin to rheumatoid gamma globulin. When we do this, we find that one molecule to every $\vec{D}$ 10 or even 100 of rheumatoid, is inhibitory. That is, the patient's own gamma globulin, present in 100 times the concentration, was unable to inhibit the reactionwhich a normal inhibitory gamma globulin, even in that $\vec{\circ}$ small proportion, could inhibit.

I think there is some difference between rheumatoid $\vec{\omega}$ and normal gamma globulin which may involve only a small portion of Cohn's Fraction II.

Dr. Morris ZIFF (New York, N.Y.): It may be that $\vec{v}$ the gamma globulin factor which sensitizes the tannic: acid treated sheep cell does so by coating the cell on the one hand, and complexing with the agglutinator on the other. In the case of the normal, untreated sensitized $\frac{\text { O }}{\square}$ cell, it may inhibit the reaction by complexing with the agglutinator but without adding to the red cell surface, $\vec{z}$ perhaps because the latter is already coated with amboceptor or because the cell surface has not been altered $\bar{\Omega}$ by tannic acid treatment.

Metabolic, Hormonal, and Anti-Rheumatic Effects of Delta-1, 9- $\alpha$-Fluoro Hydrocortisone. By ROGER L. Black, K. Lemone Yielding, Ralph E. Peterson, G. Donald Whedon, and Joseph J. Bunim, Bethesda, $M d$.

Delta-1, 9- $\alpha$-fluoro hydrocortisone (delta-1-FF) is a 요 synthetic steroid, an analogue of prednisolone, with a fluorine atom added at $\mathrm{C}^{9}$. Animal experiments by others have indicated that administration of this hormone 3 to adrenalectomized rats is followed by glycogen deposition in the liver 25 to 50 times greater than is produced by hydrocortisone, and by sodium retention five times greater than is produced by DOCA.

Studies on the antirheumatic, hormonal, and meta- $\bar{\sigma}$ bolic effects of delta-1-FF were conducted on a group of ten patients with rheumatoid arthritis and one control $\delta$ subject with mild osteo-arthritis. Sodium intake was limited to 1 or $2 \mathrm{gm}$. daily. Potassium chloride was supplemented in a 10 per cent. solution, increasing the total potassium intake to from 3 to $9 \mathrm{gm}$. daily. After $\frac{7}{0}$ daily administration of 2 to $6 \mathrm{mg}$. of this steroid, the patients with rheumatoid arthritis exhibited moderate $N$ subjective and objective improvement with gradual reduction in warmth, pain on motion, tenderness, and $\mathrm{O}$ swelling of the joints during a 2 to 4-week period. The duration of therapy ranged from 1 to 4 months.

Metabolic studies were performed on six patients including the control subject. Administration of delta1-FF was followed by prompt and marked sodium $\$$ retention. Potassium excretion was increased to a variable degree in all patients studied. Nitrogen $T^{0}$ excretion was increased slightly in only two of these six patients. Calcium and phosphorus balances in two patients to whom the drug was given for 24 and 30 days 
respectively showed no significant overall change; however, faecal calcium decreased and urinary calcium increased, suggesting increased calcium absorption during the administration of the new steroid. Glucose tolerance tests showed no change in four and a diabetic curve in one after 4 weeks of delta-1-FF administration.

Endogenous adrenal cortical steroid production, as measured by plasma hydrocortisone concentration and urinary output of corticosteroids and 17-ketosteroids, was promptly suppressed by $2 \mathrm{mg}$. delta-1-FF given orally to a normal female subject.

Oedema occurred in seven patients and in four of these precluded the administration of an adequate antirheumatic dose. Hypokalaemia occurred in six patients; the serum potassium levels were reduced to between 2.3 to $3.0 \mathrm{mEq}$. per litre, and electrocardiographic changes appeared in four patients. Elevated serum $\mathrm{CO}_{2}$ content was noted in five patients during the period of low serum potassium. Facial rounding occurred in seven patients. Repeated gastro-intestinal series at 4 to 6-week intervals failed to reveal any peptic ulcers.

Although, milligram for milligram, delta-1-FF has an antirheumatic potency approximately five times that of prednisone, its clinical usefulness in the rheumatic diseases is severely impaired by the electrolyte imbalance

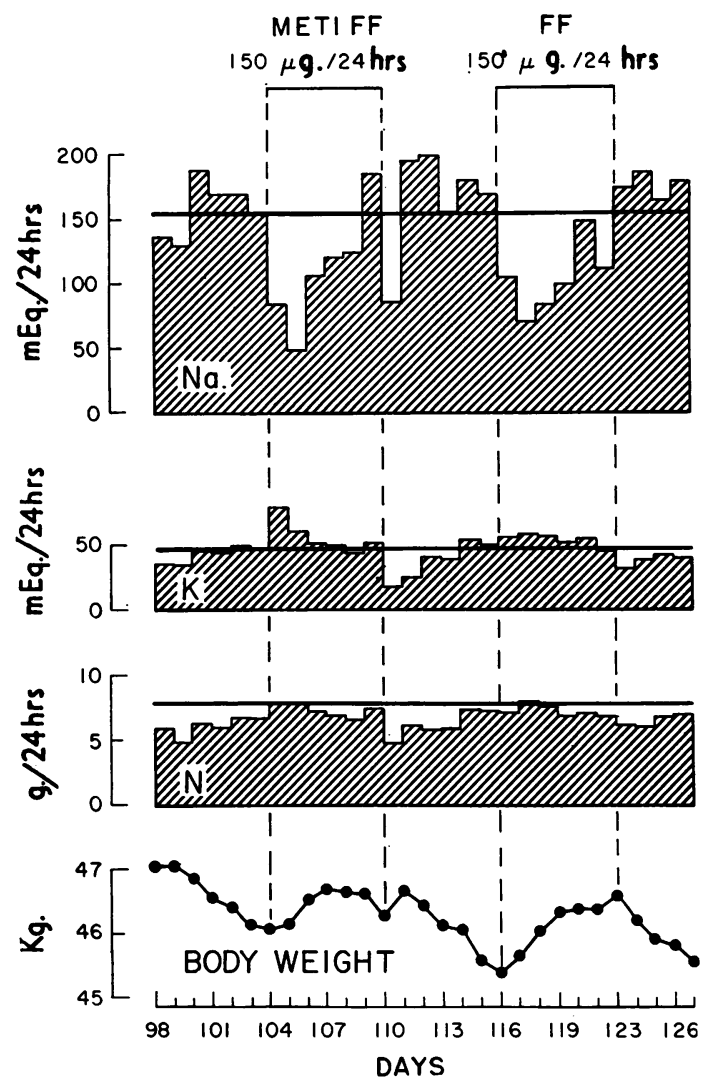

Fig. 1.-Results in a 47-year-old woman with Addison's disease. it causes. Delta-1-FF is ten times more potent than prednisone in inhibiting corticotropin secretion and suppressing adrenocortical function, which may be useful in treating certain disorders of the adrenal cortex and in studying the physiological behaviour of the pituitaryadrenal axis.

Discussion.-Dr. Maurice Pechet (Boston, Mass.): We have had considerable experience in the Heart Institute for the past year with the use of delta-1-FF (originally referred to as Meti-FF). In contrast to the studies reported to-day we carried out metabolic studies in Addisonian and normal subjects on a normal dietary intake of sodium and potassium.

Fig. 1 shows the metabolic effects of Meti-FF compared directly with those of FF (9- $\alpha$-fluoro hydrocortisone) in the same Addisonian subject. $150 \mu \mathrm{g}$. Meti-FF were administered orally daily for 6 days and after a control period $150 \mu \mathrm{g}$. FF were administered in a similar fashion. The sodium retention is similar in both instances. A loss of potassium occurred during the administration of Meti-FF and FF. At a dosage of $150 \mu \mathrm{g}$. daily there was little change in urinary nitrogen excretion.

Similar studies were carried out with normal subjects (Fig. 2). The metabolic effects associated with the oral administration of $3 \mathrm{mg}$. Meti-FF are compared with those associated with the similar administration of $3 \mathrm{mg}$. FF in the same subject. Sodium retention and increase in body weight are similar. The potassium "on-off" effect is present. On the first day of administration of the steroids there was a potassium diuresis, and on withdrawal of the steroids a retention of potassium. During the administration of Meti-FF and FF there was a considerable loss of potassium. The loss of potassium induced serum changes characteristic of hypokalaemic alkalosis. There was little change in the urinary nitrogen excretion.

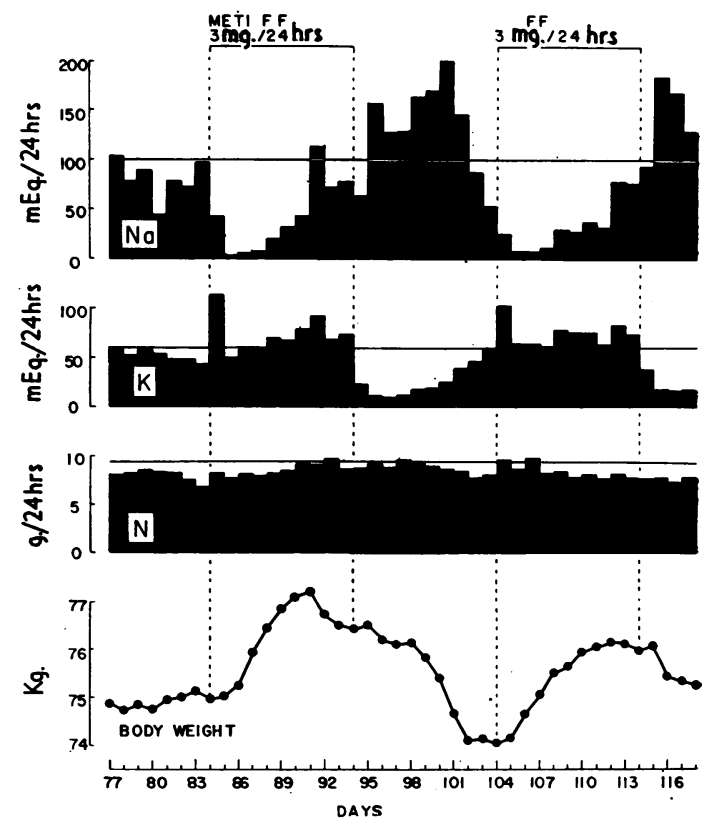

Fig. 2.-Results in a 23-year-old normal woman. 
It is apparent that the magnitude of the sodium retention and potassium loss is similar for Meti-FF and FF. Meti-FF differs from FF only in possessing an extra double bond in ring $A$ of the steroid nucleus. The introduction of the double bond in the 1,2-position of the parent steroid FF does not appreciably alter in this instance the marked sodium retaining and potassium losing properties of the parent steroid FF. Though Meti-FF and FF are valuable steroids in the treatment of Addison's disease, they are drugs which require a great deal of caution in their ordinary use.

DR. Black: I certainly agree with your comment. That would be our feeling about the drug, also.

Dr. D. M. Bergenstal (Bethesda, Md): Dr. M. C. Li, Dr. Roy Hertz, and I have had the opportunity in the Endocrine Division of the National Cancer Institute of studying delta-1-FF for some months, and have been using doses of 2 to $10 \mathrm{mg}$. a day much higher than those reported by Dr. Black. We were trying to suppress pituitary ACTH formation enough to produce medical adrenalectomy for the control of breast cancer. We were able to show, as Dr. Black has shown, that we could suppress 17-ketosteroid formation and corticosteroid formation. If, however, one continues the administration of this drug for 1 to 2 weeks, there seems to be an escape phenomena, in that the 17-ketosteroids and urinary corticosteroids begin to rise and may return to nearly normal levels. This was observed even on doses of $10 \mathrm{mg}$. of delta-1-FF a day. Thus this compound does not seem to cause a prolonged depression of adrenal function.

We were interested in its ability to maintain adrenalectomized patients in a state of good health, for it is our feeling that cortisone used to maintain an adrenalectomized patient may be converted to oestrogen and androgen and cause a relapse of the tumour. We were able to maintain an adrenalectomized patient on as little as $1 \mathrm{mg}$. delta-1-FF a day in very good clinical condition, and we feel that this amount of material would probably not be converted to oestrogen and androgen.

We have done balance studies and have confirmed the findings of Dr. Brown and the investigators at the National Heart Institute, in that it produces a marked sodium retention with an escape phenomena after 10 days or so at a time when we began to get a sodium diuresis despite the continuation of high doses. There is also a marked loss of potassium with the development of hypokalaemia and we have observed changes in the electrocardiogram indicating a hypokalaemia.

We feel that this compound is more of a nitrogen and potassium loser than 9- $\alpha$-fluoro hydrocortisone, milligram per milligram, and it seems to be more potent in depressing the eosinophil count than is $9-\alpha$-fluoro hydrocortisone. As pointed out, it is a very potent drug, and should be given with great caution, watching particularly for the development of hypokalaemia.

Dr. Morris Ziff (New York, N.Y.): Why do these compounds, 9- $\alpha$-fluoro hydrocortisone and prednisone, which are synthetic and presumably do not occur in the body, so much more effective than the naturally occurring compound in suppressing adrenal function? If, as is commonly believed, the serum level determines the degree of suppression of the pituitary, this makes one wonder whether it is really hydrocortisone that controls the rate of secretion of the pituitary.

DR. BLACK: This is a very interesting point, but one which I am not prepared to answer now.
Papers Presented by Title Only

Metabolic and Enzymatic Adaptation in Animals. By Victor H. Auerbach, ${ }^{*}$ Cambridge, Mass.

Sjögren's Syndrome: A Study of Eight Cases. By $\underset{\vec{D}}{\vec{D}}$ Charles W. Denko* and Delbert M. Bergenstal, Chicago, Ill.

Comparative Susceptibility to Collagenase and Trypsin of Collagen, Soluble Collagens, and Renal Basement Membrane. By Ellis Dresner* and MAXwell SCHUBERT, New York, N.Y.

Histochemical Studies in the Skin of Man with a Type of Bio-Assay Technique for Corticosteroids with Prolonged Local Activity. By Leon Goldman, Cincinnati, Ohio.

Effect of Salicylate and Butazolidin on Pituitary Adrenal Function in Guinea-Pigs. By Thomas A. GooD* and Vincent C. Kelley, Salt Lake City, Utah.

Comparative Effectiveness of Intra-Articular Prednisone, Prednisolone, and Prednisolone Esters in Arthritic Joints. By Joseph L. Hollander, Philadelphia, Pa.

Syndrome of Osteo-Arthritis, Non-Articular Tenderness, Personality Disorder, and Characteristic Life Situation. By J. H. IRVINE, New York, N.Y.

Mechanism of Steroid Glucuronide Formation. By KURT J. IsSELBACHER, Bethesda, Md.

Cartilage Mucoprotein and the Diffusibility of Dyes through Cartilage. By ThOMAs G. Kantor and MaXWell Schubert, New York, N.Y.

Osteo-Arthrosis-_Iatrogenic Arthritis". By H. KLINEFELTER, JR., Baltimore, $M d$.

Quantitation of the "Activity" of Rheumatoid Arthritis. By John Lansbury, Philadelphia, $\mathrm{Pa}$.

Histopathology of Synovial Membrane. By F. W. McCoy, Columbus, Ohio.

Treatment of Hip-Joint Disabilities: End-Result Study of the Resection-Angulation Operation. By HENRY Much, New York, N.Y.

Effect of Complete Adrenalectomy in Rheumatoid Arthritis. By R. D. Miller, Pasadena, Calif.

Clinical and Metabolic Effects of Prednisone and Prednisolone in Rheumatoid Arthritis. By DAVID $\mathrm{H}$. Neustadt, Robert McClendon, and F. A. Olash, Louisville, Ky.

Sources of Normal Synovial Fluids. By WARD PIGMAN, David Platt, * Francis Patton, and Howard L. Holley, Birmingham, Ala.

Persistent Hyperlipaemia following Injection of a Lipid Mobilizer obtained from Plasma of Cortisonized Animals and Humans. By JoSEPH SEIfTER and David H. Baeder, Philadelphia, Pa.

Reactions of Intra-Articular Temperature to Vasoconstriction and Vasodilatation of the Extremities. By Nathan M. Smukler and Raymond Penneys, Philadelphia, Pa.

* Fellow of the Arthritis and Rheumatism Foundation. 
Effect of Remote Inflammation on the Granuloma Pouch. By Arthur I. Snyder, ${ }^{*}$ New York, N.Y.

Specific Amelioration of Focal Myocardial Reactions to Bovine Gamma Globulin. Preliminary Observations. By OSCAR Swineford, JR.* and Rudolph HOENe, Charlottesville, $\mathrm{Va}$.

Effect of 9- $\alpha$-Fluoro Hydrocortisone on the Electrolyte Content of the Contracting Cat Papillary Heart

* Fellow of the Arthritis and Rheumatism Foundation.
Muscle. A Preliminary Report. By RALPH D. Tanz, Glenn M. Clark, and Richard W. WhiteHEAD, Denver, Colo.

Diurnal Plasma Corticoid Studies and their relation to Morning Stiffness in Rheumatoid Arthritis. By Joseph E. WARren, Pittsburgh, $P a$.

Acquisition of Increasing Resistance to Nitrogen Mustards by transforming Mononuclear Blood Cells in Tissue Culture. By Leon P. Weiss and Carlton Smith, Boston, Mass. 